\title{
Analysis of Factors Affecting a Driver's Driving Speed Selection in Low Illumination
}

\author{
Jing Liu $\mathbb{D},{ }^{1,2}$ Jing Cai, ${ }^{1}$ Shanshan Lin, ${ }^{3}$ and Jianyou Zhao ${ }^{1}{ }^{1}$ \\ ${ }^{1}$ School of Automobile, Chang'an University, Xi'an, Shaanxi 710064, China \\ ${ }^{2}$ School of Mechanical and Electrical Engineering, Anhui Jianzhu University, Hefei, Anhui, ST 230601, China \\ ${ }^{3}$ School of Automobile and Traffic Engineering, Hefei University of Technology, Hefei 230009, Anhui, China
}

Correspondence should be addressed to Jing Liu; liujing1102@ahjzu.edu.cn

Received 17 December 2019; Revised 8 February 2020; Accepted 14 February 2020; Published 21 April 2020

Guest Editor: Feng Chen

Copyright ( $) 2020$ Jing Liu et al. This is an open access article distributed under the Creative Commons Attribution License, which permits unrestricted use, distribution, and reproduction in any medium, provided the original work is properly cited.

\begin{abstract}
To better understand a driver's driving speed selection behaviour in low illumination, a self-designed questionnaire was applied to investigate driving ability in low illumination, and the influencing factors of low-illumination driving speed selection behaviour were discussed from the driver's perspective. The reliability and validity of 243 questionnaires were tested, and multiple linear regression was used to analyse the comprehensive influence of demographic variables, driving speed in a low-illumination environment with street lights and driving ability on speed selection behaviour in low illumination without street lights. Pearson's correlation test showed that there was no correlation among age, education, accidents in the past 3 years, and speed selection behaviour in low illumination, but gender, driving experience, number of night-driving days per week, and average annual mileage were significantly correlated with speed selection behaviour. In a low-illumination environment, driving ability has a significant influence on a driver's speed selection behaviour. Technical driving ability under low-illumination conditions of street lights has the greatest influence on speed selection behaviour on a road with a speed limit of $120 \mathrm{~km} / \mathrm{h}(\beta=0.51)$. Risk perception ability has a significant negative impact on speed selection behaviour on roads with speed limits of $80 \mathrm{~km} / \mathrm{h}$ and $120 \mathrm{~km} / \mathrm{h}$ ( $\beta=-0.25$ and $\beta=-0.34$, respectively). Driving speed in night-driving environment with street lights also has a positive influence on speed selection behaviour in low illumination $(\beta=0.61 ; \beta=0.28 ; \beta=0.37)$.
\end{abstract}

\section{Introduction}

Night accidents are frequent and serious. Among the total number of traffic accidents, $46 \%$ to $54 \%$ of accidents occurred at night, while the traffic volume during this period was $10 \% \sim 30 \%$ of that in the daytime, causing approximately $60 \%$ of the total number of deaths [1]. The probability and severity of traffic accidents in low-illumination environmental conditions at night are much higher than those in the daytime. A study on truck-involved accidents has found that the probability of severe injury increases in the low illumination condition [2].

The driver is in a dominant position in the transportation system. Studies have shown that motor vehicle drivers are one of the main factors leading to traffic accidents. According to statistics, 80 to $90 \%$ of road traffic accidents in China are caused by human factors, especially driving behaviours, as traffic accidents caused by driving errors constitute $70-80 \%$ [3].

A series of studies have been carried out on the effects of illumination on driving behaviours, especially drivers' visual characteristics. Previous studies have examined the effect of illumination on visual sensitivity. These studies found that visual sensitivities decrease linearly with a decrease in illumination [4]. Rackoff and Rockwell showed that the safety of driving at night could be improved by increasing environmental illumination to meet drivers' demands for visual information [5]. A comparative test of low illumination and normal illumination was conducted to analyse the effects of environmental illumination and speed on the recognition time of objects with different colors, and a measurement model of vehicle speed, dynamic low illumination, and 
recognition time was built [6]. Driver's visual characteristics and cognitive ability are directly affected by insufficient illumination; thus, driving behaviour is also affected, showing a difference from normal illumination conditions.

In the process of driving, more than $90 \%$ of the information that the driver has is obtained by visual perception [7]. Through continuous perception of road environment information, the driver can make behavioural decisions and guide the cyclic feedback process of driving behaviour [8]. Most traffic accidents are caused by poor line-of-sight conditions [9]. In a dark night environment, it is difficult to form a clear image on the retina due to insufficient light entering the driver's eyes, so it is more difficult for the driver to perceive road environment information. Whether the driver can accurately visualize an obstacle in front, the difference between the brightness of the obstacle and the contrast of the environment, and the illumination of the environment in which the driver is located are important factors. As the illumination of the driver's environment increases, the driver's visibility of an obstacle will be reduced due to the high brightness of the surrounding environment [10].

The influence of illumination on the speed selection and safety of drivers has been studied by many scholars. A study found that illumination could affect a drivers' speed selection and attention during driving and that an increase in illumination could reduce the occurrence of accidents [11]. Haglund and Aberg found that $47 \%$ 58\% of drivers overspeed at night, and their self-perceived speed is lower than the actual speed [12]. With insufficient lighting at night, the driver's perception of speed will be illusory. Suh and Park and other studies found that insufficient night lighting will make the driver feel that the speed of the vehicle is not fast, causing the driver to accelerate or even speed [13]. Baker found that night drivers underestimated speed and increased driving speed [14]. Read and others found that in the study of the effect of improving the brightness of street lamps on the driving performance of elderly individuals at night, the driver increased speed and reduced attention when road lighting was installed [15]. Under certain conditions, an increase in road brightness is helpful to some drivers, but in other cases, it has a negative impact on the driver. In addition, low illumination affects the driver's speed processing ability. A reduction in illumination seriously affects visual ability, reduces reaction time, and reduces speed processing capability.

Driving is a complex sensory movement task. Good driving ability is also a prerequisite for ensuring safe driving of drivers. Driving ability includes technical driving ability and risk perception ability. In low illumination, a driver's driving ability will also change to a certain extent, which in turn affects the driver's speed selection behaviour. However, there are few studies on driving ability and speed selection behaviour in low illumination at home and abroad.

Therefore, the purpose of this paper is to study the influence of driving ability on speed selection behaviour in low-illumination conditions and combine the driver's personal attributes to separately analyse speed selection behaviours under the two scenarios of street lights at night and no street lights at night. The corresponding data were obtained through a questionnaire survey, and a multiple regression model of driving speed selection in low illumination was established to provide a theoretical basis for road speed management in low illumination.

\section{Research Methods}

2.1. Measures. The existing methods of researching driver behaviours can be divided into driving simulator technology [16], real-time driving environmental big data [17], real vehicle experiment [18], mathematical model [19], and questionnaires [20]. Different from the former methods, the latter one measures the behaviours via psychological perspective. In the present study, a questionnaire instrument was used, which is a cost-effective way in examining driver behaviours based on psychological characteristics.

According to the purpose of this study, the "driver survey questionnaire in low illumination" consists of three parts: driver demographic information, speed selection behaviour, and driving ability scale in low illumination. The selection of items was mainly based on mature questionnaires that have been widely used in the industry and screening from the items of those questionnaires. In addition, drivers were interviewed, and the interview results showed that a driver's sensitivity to illumination was poor and that the perception and understanding of low illumination were different. Therefore, the questionnaire did not define low illumination by light intensity but described a low-illumination environment as a "night environment."

After the preliminary design and formation of the questionnaire, teachers and graduate students of the Traffic Safety Institute were invited to conduct evaluations, and 10 professional drivers were invited to pre-fill according to driving situations in low illumination in the past year and to propose amendments. Finally, some questions were adjusted, modified, and replaced. The specific design contents of the questionnaire were as follows:

2.1.1. Demographic Information. The demographic information included gender, age, driving experience, education, average annual mileage, number of night-driving days per week, number of traffic accidents that occurred at night in the past three years, deduction in 2017, deduction due to low illumination, and self-assessment of the influence of a lowillumination environment on driving performance and driving skills.

2.1.2. Speed Selection Behaviour. The speed limit value has a significant impact on driving speed, and a driver will choose to increase or decrease speed with a change in the road speed limit value [21]. Therefore, this study combines road classification and common speed limit values to classify roads into three types: urban roads/low-grade highways (speed limit: $60 \mathrm{~km} / \mathrm{h}$ ), high-grade highways (speed limit: $80 \mathrm{~km} / \mathrm{h}$ ), and expressways (speed limit: $120 \mathrm{~km} / \mathrm{h}$ ). Drivers were asked to answer six questions about speed selection: in nightdriving environment with street lights, the driving speed 
(WSL60) that is preferred on a road with a speed limit of $60 \mathrm{~km} / \mathrm{h}$; in night-driving environment without street lights, the driving speed (WOSL60) that is preferred on a road with a speed limit of $60 \mathrm{~km} / \mathrm{h}$; in night-driving environment with street lights, the driving speed (WSL80) that is preferred on a road with a speed limit of $80 \mathrm{~km} / \mathrm{h}$; in night-driving environment without street lights, the driving speed (WOSL80) that is preferred on a road with a speed limit of $80 \mathrm{~km} / \mathrm{h}$; in night-driving environment with street lights, the driving speed (WSL120) that is preferred on a road with a speed limit of $120 \mathrm{~km} / \mathrm{h}$; and in night-driving environment without street lights, the driving speed (WOSL120) that is preferred on a road with a speed limit of $120 \mathrm{~km} / \mathrm{h}$.

\subsubsection{Driving Ability Scale in Low Illumination.} Referring to the driving skills assessment questionnaire designed by Zheng [22], the traffic scenario was set as a lowillumination environment at night and was specifically divided into two scenarios of street lights at night and no street lights at night. The specific contents are shown in Tables 1 and 2. Drivers were required to self-report by scoring on the form to evaluate their driving ability in a low-illumination environment at night. Each item was scored in the form of a Likert 5-point scale, from " $1=$ completely inconsistent" to " $5=$ completely consistent." The items were set in the opposite direction; the lower the score was, the better the driving ability was.

2.2. Experimental Process. The questionnaire was conducted through a field survey, and drivers were required to fill in the questionnaire according to their actual driving conditions in low illumination at night. Participants participated in the survey voluntarily and anonymously, and it took approximately 10 minutes to complete the questionnaire. The driver will be paid 10 yuan after the investigation is completed.

2.3. Data Collection. A total of 266 questionnaires were collected in this survey, and 243 valid questionnaires were finally collected, excluding those that were incomplete or had less than one year of driving experience. Participants included 182 men and 61 women, with an average age of 31.9 years $(\mathrm{SD}=7.319)$ and ages ranging from 20 to 55 years old; average driving experience of 5.6 years $(\mathrm{SD}=5.127)$; and average annual mileage of 160.27 million kilometres $(\mathrm{SD}=2.1119)$. The average number of night-driving days per week was 2.426 days $(\mathrm{SD}=1.8644)$, the average deduction in 2017 was $2.35(\mathrm{SD}=3.449)$, and the average deduction due to low illumination at night was $0.18(\mathrm{SD}=0.72)$.

\section{Results}

3.1. Descriptive Analysis. Under the condition with street lights, the average driving speed of a driver is $58.61 \mathrm{~km} / \mathrm{h}$ $(\mathrm{SD}=8.795), 77.13 \mathrm{~km} / \mathrm{h} \quad(\mathrm{SD}=8.654)$, and $110.88 \mathrm{~km} / \mathrm{h}$ $(\mathrm{SD}=10.594)$ on roads with speed limits of $60 \mathrm{~km} / \mathrm{h}, 80 \mathrm{~km} /$ $\mathrm{h}$, and $120 \mathrm{~km} / \mathrm{h}$, and the corresponding speed reduction in night-driving environment with street lights is $14.09 \%$
$(M=50.35 \mathrm{~km} / \mathrm{h}, \quad \mathrm{SD}=10.139), \quad 18.13 \% \quad(M=63.15 \mathrm{~km} / \mathrm{h}$, $\mathrm{SD}=7.811)$, and $11.89 \%(M=97.70 \mathrm{~km} / \mathrm{h}, \mathrm{SD}=7.360)$, respectively; that is, a driver will drive at a speed approximately $15 \%$ lower than normal when driving in a low-illumination environment.

3.2. Reliability and Validity Analysis. To ensure the reliability and validity of the research results, it is necessary to test the reliability and validity of the self-compiled driving ability scale in low illumination. Among the results, the Kaiser-Meyer-Olkin (KMO) value of the driving ability scale in the case of street lights at night is 0.937 , which is greater than the standard value of 0.5 , and the Bartlett sphericity test result reaches the level of significance $(p<0.01)$. The KMO value of the driving ability scale in the case of no street lights at night is 0.948 , which is greater than the standard value of 0.5 , and the Bartlett sphericity test results reach the level of significance $(p<0.01)$, indicating that the data are suitable for factor analysis [23].

Principal component analysis was used to conduct the maximum rotation of variance for the driving ability scale with and without street lights at night. In the case of street lights at night, the driving ability scale obtains two factors with eigenvalues greater than 1, named "Technical Driving Ability 1" (TDA1) and "Risk Perception Ability 1" (RPA1). The questionnaire consists of 16 items, these two factors explain $81.62 \%$ of the total variance, and the load of each item is above 0.66 . The specific results are shown in Table 1. The factor structure agrees with the theoretical conception, and the validity of the questionnaire structure is good.

In the case of no street lights at night, the driving ability scale obtains two factors with eigenvalues greater than 1, named "Technical Driving Ability 2" (TDA2) and "Risk Perception Ability 2" (RPA2). The questionnaire consists of 22 items, these two factors explain $76.34 \%$ of the total variance, and the load of each item is above 0.71 . The specific results are shown in Table 2 . The factor structure agrees with the theoretical conception, and the validity of the questionnaire structure is good.

Cronbach's $\alpha$ coefficients were used for reliability analysis of the scale to measure its reliability. When $\alpha>0.7$, the questionnaire is acceptable. Cronbach's $\alpha$ coefficient of the driving ability scale for street lights at night used in this study is 0.976 , and the combined reliability of the two factors is 0.962 and 0.969; Cronbach's $\alpha$ coefficient of the driving ability scale for no street lights at night is 0.975 , and the combined reliability of the two factors is 0.961 and 0.975 , indicating that the questionnaires have ideal reliability.

3.3. Correlation Analysis. The Pearson correlation coefficient method is adopted to measure the correlation between a driver's personal attributes and speed selection behaviour in low illumination without street lights. The specific results are shown in Table 3. The gender of the driver and average number of night-driving days per week are significantly correlated with speed selection behaviour on roads with speed limits of $60 \mathrm{~km} / \mathrm{h}$ and $80 \mathrm{~km} / \mathrm{h}$, respectively, in nightdriving environment without street lights; driving 
TABLE 1: Factor structure and load of the driving ability scale in environments with street lights at night.

\begin{tabular}{|c|c|c|c|}
\hline Item & Item content & TDA1 & RPA1 \\
\hline 1 & When there are street lights at night, I can control the vehicle smoothly on the road & 0.85 & \\
\hline 2 & When there are street lights at night, I can control the vehicle steadily on slippery roads & 0.82 & \\
\hline 4 & When there are street lights at night, I can park safely and correctly on the ramp & 0.84 & \\
\hline 8 & I have mastered the methods and techniques of emergency steering at night with street lights & 0.67 & \\
\hline 13 & When there are street lights at night, I can always safely avoid in case of an emergency & 0.82 & \\
\hline 21 & $\begin{array}{c}\text { When there are street lights at night, I can drive reasonably by observing the movements of pedestrians and other } \\
\text { vehicles }\end{array}$ & 0.73 & \\
\hline 23 & When there are street lights at night, I can overtake safely and reasonably & 0.82 & \\
\hline 12 & When there are street lights at night, I can plan or choose routes to avoid getting lost and taking long detours & & 0.70 \\
\hline 14 & When there are street lights at night, I can detect potential traffic dangers on the road & & 0.77 \\
\hline 16 & When there are street lights at night, I can keep a safe driving distance from the vehicle in front & & 0.85 \\
\hline 17 & $\begin{array}{l}\text { When there are street lights at night, I can get a good grasp of the surrounding traffic situation when driving the } \\
\text { vehicle }\end{array}$ & & 0.76 \\
\hline 18 & When there are street lights at night, I can react quickly in case of an emergency during driving & & 0.84 \\
\hline 20 & When there are street lights at night, I can make a quick decision when I encounter a choice during driving & & 0.83 \\
\hline 22 & When there are street lights at night, I can notice the dynamic state of the roadside & & 0.84 \\
\hline 24 & When there are street lights at night, I can judge the safe speed of the road according to different road conditions & & 0.81 \\
\hline 25 & When there are street lights at night, I can pay attention to the dynamics near my vehicle while driving & & 0.80 \\
\hline
\end{tabular}

TABLE 2: Factor structure and load of the driving ability scale in environments with no street lights at night.

\begin{tabular}{|c|c|c|c|}
\hline Item & Item content & TDA1 & RPA1 \\
\hline 28 & When there is no street light at night, I can control the vehicle smoothly on the road & 0.78 & \\
\hline 29 & When there is no street light at night, I can control the vehicle steadily on slippery roads & 0.79 & \\
\hline 31 & When there is no street light at night, I can park safely and correctly on the ramp & 0.78 & \\
\hline 32 & I can drive steadily and safely at night without street lights & 0.82 & \\
\hline 33 & $\begin{array}{c}\text { When there is no street light at night, I can drive the vehicle smoothly at night (such as slow acceleration and } \\
\text { deceleration) }\end{array}$ & 0.85 & \\
\hline 35 & I have mastered the methods and techniques of emergency steering at night without street lights & 0.75 & \\
\hline 36 & I mastered the skills of braking quickly and controlling the & 0.73 & \\
\hline 37 & When there is no street light at night, I can still complete the nec & 0.76 & \\
\hline 38 & When there is no street light at night, I can skilfully use various electronic navigation equipment in the vehicle & 0.75 & \\
\hline 46 & When there is no street light at night, I can change lan & 0.76 & \\
\hline 51 & When there is no street light at night, I can & 0.77 & \\
\hline 30 & here is no street light at night, I will observe the surrounding & & 0.79 \\
\hline 34 & When there is no street light at night, I can adjust the driving speed according to the driving situation & & 0.86 \\
\hline 44 & $\begin{array}{c}\text { When there is no street light at night, I can get a good grasp of the surrounding traffic situation when driving the } \\
\text { vehicle }\end{array}$ & & 0.82 \\
\hline 45 & uickly in case of an emergency during driving & & 0.81 \\
\hline 47 & When there is no street light at night, I can make a quick decision when I encounter a choice during driving & & 0.80 \\
\hline 48 & $\begin{array}{c}\text { When there is no street light at night, I can drive reasonably by observing the movements of pedestrians and other } \\
\text { vehicles }\end{array}$ & & 0.83 \\
\hline 50 & When there is no street light at night, I c & & 0.72 \\
\hline 52 & When there is no stre & & 0.80 \\
\hline 53 & When there is no street light at night, I can pay attention to the dynamics near my vehicle while driving & & 0.87 \\
\hline 54 & s of other drivers. & & 0.83 \\
\hline 55 & When there is no street light at night, I can quickly identify pedestrians crossing the road ahead & & 0.87 \\
\hline
\end{tabular}

experience is significantly related to speed selection behaviour on a road with a speed limit of $80 \mathrm{~km} / \mathrm{h}$; total annual deduction is significantly related to speed selection behaviour on a road with a speed limit of $60 \mathrm{~km} / \mathrm{h}$; and the average annual mileage is significantly correlated with the speed selection behaviour on roads with speed limits of $60 \mathrm{~km} / \mathrm{h}$ and $120 \mathrm{~km} / \mathrm{h}$. Speed selection behaviour in low illumination without street lights is significantly correlated with speed selection behaviour in night-driving environment with street lights with speed limits of $60 \mathrm{~km} / \mathrm{h}, 80 \mathrm{~km} / \mathrm{h}$, and $120 \mathrm{~km} / \mathrm{h}$, respectively. Age, education, and accidents in the past 3 years are not correlated with speed selection behaviour in nightdriving environment with street lights.

3.4. Difference Analysis. An independent $t$-test was used to analyse the differences in speed selection behaviour for different driving experience and average annual mileage in a low-illumination environment without street lights. The specific results are shown in Table 4 . The results show that 
TABLE 3: Correlation analysis between a Driver's personal attributes and speed selection behaviour in low illumination.

\begin{tabular}{lccc}
\hline & WOSL60 & WOSL80 & WOSL120 \\
\hline Gender & $0.143^{*}$ & $0.240^{* *}$ & 0.096 \\
Age & 0.006 & 0.115 & 0.040 \\
Education & 0.004 & -0.103 & 0.001 \\
Driving experience & 0.109 & $0.147^{*}$ & 0.090 \\
Average annual mileage & $0.182^{*}$ & 0.107 & $0.203^{* *}$ \\
Number of night-driving days & $0.229^{* *}$ & $0.129^{*}$ & -0.074 \\
per week & $0.164^{*}$ & 0.086 & 0.121 \\
Deduction in the past year & 0.031 & -0.065 & 0.054 \\
Accidents in the past 3 years & $0.665^{* *}$ & $0.255^{* *}$ & $0.220^{* *}$ \\
WSL60 & $0.566^{* *}$ & $0.457^{* *}$ & $0.328^{* *}$ \\
WSL80 & $0.398^{* *}$ & $0.439^{* *}$ & $0.388^{* *}$ \\
WSL120 & & & \\
\hline
\end{tabular}

drivers tend to choose the speeds WOSL60, WOSL80, and WOSL120 in a low-illumination environment without street lights with road speed limits of $60 \mathrm{~km} / \mathrm{h}, 80 \mathrm{~km} / \mathrm{h}$, and $120 \mathrm{~km} / \mathrm{h}$, respectively, that have significant differences in terms of driving experience and average annual mileage. Under the same speed limit conditions, the greater the driving experience and the higher the average annual mileage are, the higher the speed selection in a low-illumination environment.

3.5. Predictors of Speed Selection Behaviour. Since the driving ability of a driver in low illumination cannot be directly observed, multiple linear regression analysis is used in this paper to predict the preferred speeds WOSL60, WOSL80, and WOSL120 in a low-illumination environment without street lights with speed limits of $60 \mathrm{~km} / \mathrm{h}, 80 \mathrm{~km} / \mathrm{h}$, and $120 \mathrm{~km} / \mathrm{h}$, respectively, as shown in Table 5 . The driver's gender, age, education, driving experience, average annual mileage, number of night-driving days per week, total annual deduction, and accidents in the past 3 years are taken as demographic variables and included in the regression model as the first step. The driving speeds that a driver tends to choose on roads with the three different speed limit conditions in a low-illumination environment with street lights are gradually incorporated into the regression model in the second step. The driving skills under street lights at night and the driving skills under no street lights at night are gradually incorporated into the regression model in the third step.

The total explanatory power of the regression model for WOSL60 is $48.3 \%$, among which the driver's number of night-driving days per week, WSL60, and WSL120 are significant predictors. Demographic variables have 10.9\% explanatory power $(F(8,234)=3.581, p=0.001)$, WSL60 has $38.1 \%$ explanatory power $(F \quad(9,233)=24.847$, $p=0.000)$, and WSL120 has $1.5 \%$ explanatory power ( $F$ $(10,232)=23.629, p=0.000)$.

The total explanatory power of the regression model for WOSL80 is $37.4 \%$, among which the driver's gender, education, total annual deduction, WSL80, WSL120, TDA1, and RPA1 are significant predictors. The explanatory power of demographic variables is $12.9 \% \quad(F \quad(8,234)=4.318$, $p=0.000)$. The explanatory power of WSL80 and WSL120 for WOSL80 is $16.9 \%(F(9,233)=10.977, p=0.000)$ and $4 \%$ $(F(10,232)=11.818, p=0.000)$, respectively, indicating that the higher the driver's preferred speed is on a road with street lights and an $80 \mathrm{~km} / \mathrm{h}$ or $120 \mathrm{~km} / \mathrm{h}$ speed limit, the higher the driver's preferred speed on a road with an $80 \mathrm{~km} /$ $\mathrm{h}$ speed limit in a low-illumination environment. In addition, the explanatory power of RPA1 is $1.8 \%(F(12,230)=$ $13.026, p=0.000$ ), and the explanatory power of TDA 1 to WOSL80 is $4.9 \%(F(11,231)=13.223, p=0.000)$, indicating that the stronger the driver's technical driving ability is under the condition of street lights at night, the higher the speed the driver tends to choose on a road with a speed limit of $80 \mathrm{~km} / \mathrm{h}$ in a low-illumination environment. However, the stronger that risk perception ability is under the condition of street lights at night, the lower the speed selection is.

The driver's number of night-driving days per week, total annual deduction, WSL120, TDA1, and RPA2 are significant predictors of WOSL120, and the total explanatory power of the regression model is $30.9 \%$. Among them, the explanatory power of demographic variables is $7.5 \%(F(8,234)=2.373$, $p=0.018)$, and the explanatory power of WSL120 to WOSL120 is $14.7 \%(F(9,233)=7.371, p=0.000)$, indicating that the higher the driver's preferred speed is on a road with street lights conditions and a speed limit of $120 \mathrm{~km} / \mathrm{h}$, the higher the driver's preferred speed on a road with a speed limit of $120 \mathrm{~km} / \mathrm{h}$ in a low-illumination environment without street lights. The explanatory power of TDA 1 is $6.8 \%$ $(F(10,232)=9.437, p=0.000)$, indicating that the more skilled the driver is at driving with street lights at night, the higher the value of WOSL120. RPA2 has a minimum explanatory power of $5.1 \%(F(11,231)=10.819, p=0.000)$, indicating that the higher the driver's risk perception ability is under the condition of street lights at night, the lower the value of WOSL120 is.

\section{Discussion}

This study aims to explore the relationships between speed selection behaviour and demographic variables and driving ability in a low-illumination environment by questionnaires and analysis. The results show that there are significant differences in terms of driving experience and average annual mileage affecting drivers' preferred speeds in a lowillumination environment. Drivers' driving skills in a lowillumination environment have a significant predictive effect on speed selection behaviour. In addition, gender, driving experience, average annual mileage, average number of night-driving days per week, and total annual deduction were found to be significantly correlated with speed selection behaviour in low illumination without street lights.

4.1. Validation of the Driving Ability Scale. Based on previous questionnaire designed by Zheng [22], we confirmed the validation of the newly developed scale concerning a lowillumination environment at night and the scenarios of street lights at night/no street lights at night. In the case of street lights at night, it yielded 2 factors explaining $81.62 \%$ of the variance, Cronbach's $\alpha$ values of factors were above 0.9 , and 
TABLE 4: Difference analysis of speed selection behaviour in low illumination.

\begin{tabular}{|c|c|c|c|c|c|c|}
\hline \multirow{2}{*}{ Variable } & \multicolumn{2}{|c|}{ Driving experience $M(\mathrm{SD})$} & \multirow{2}{*}{$T$} & \multicolumn{2}{|c|}{ Average annual mileage $M$ (SD) } & \multirow{2}{*}{$T$} \\
\hline & $<6$ years & $\geq 6$ years & & $<15,000 \mathrm{~km}$ & $\geq 15,000 \mathrm{~km}$ & \\
\hline WOSL60 & $48.91(10.450)$ & $52.89(9.080)$ & $2.986^{* * *}$ & $48.39(9.782)$ & $53.41(9.974)$ & $3.878^{* * *}$ \\
\hline WOSL80 & $61.94(7.674)$ & $65.28(7.632)$ & $3.276^{* * *}$ & $62.09(7.308)$ & $64.79(8.313)$ & $2.657^{* *}$ \\
\hline WOSL120 & $96.84(7.253)$ & $99.20(7.346)$ & $2.433^{*}$ & $96.45(7.125)$ & $99.63(7.338)$ & $3.354^{* * *}$ \\
\hline
\end{tabular}

${ }^{*} p<0.05,{ }^{* *} p<0.01$, and ${ }^{* * *} p<0.005$.

TABLE 5: Regression prediction model of speed selection behaviour in low illumination.

\begin{tabular}{|c|c|c|c|c|c|c|}
\hline \multirow{2}{*}{ Variable } & \multicolumn{2}{|c|}{ WOSL60 } & \multicolumn{2}{|c|}{ WOSL80 } & \multicolumn{2}{|c|}{ WOSL120 } \\
\hline & $\Delta R^{2}$ & $\beta$ & $\Delta R^{2}$ & $\beta$ & $\Delta R^{2}$ & $\mathrm{~B}$ \\
\hline Step 1: enter & \multicolumn{2}{|c|}{0.109} & \multicolumn{2}{|c|}{0.129} & \multicolumn{2}{|c|}{0.075} \\
\hline Gender & & 0.002 & & $0.124^{*}$ & & 0.049 \\
\hline Age & & -0.06 & & -0.007 & & -0.1 \\
\hline Education & & -0.068 & & $-0.141^{* *}$ & & -0.018 \\
\hline Driving experience & & 0.109 & & 0.041 & & 0.036 \\
\hline Average annual mileage & & 0.042 & & -0.086 & & 0.047 \\
\hline Number of night-driving days per week & & $0.114^{*}$ & & -0.006 & & $-0.204^{* * *}$ \\
\hline Deduction in the past year & & 0.066 & & $-0.149^{* *}$ & & $0.136^{*}$ \\
\hline Accidents in the past 3 years & & -0.042 & & -0.101 & & 0.003 \\
\hline \multicolumn{7}{|l|}{ Step 2: stepwise } \\
\hline WSL60 & 0.381 & $0.609^{* * *}$ & & & & \\
\hline WSL80 & & & 0.169 & $0.277^{* * *}$ & & \\
\hline WSL120 & 0.015 & $0.139^{* *}$ & 0.04 & $0.223^{* * *}$ & 0.147 & $0.374^{* * *}$ \\
\hline \multicolumn{7}{|l|}{ Step 3: stepwise } \\
\hline TDA1 & & & 0.049 & $0.445^{* * *}$ & 0.068 & $0.513^{* * *}$ \\
\hline RPA1 & & & 0.018 & $-0.248^{* *}$ & & \\
\hline \multicolumn{7}{|l|}{ TDA2 } \\
\hline \multirow[t]{2}{*}{ RPA2 } & & & & & 0.051 & $-0.343^{* * *}$ \\
\hline & $R^{2}=0.483$ & & $R^{2}=0.374$ & & $R^{2}=0.309$ & \\
\hline
\end{tabular}

${ }^{*} p<0.05,{ }^{* *} p<0.01$, and ${ }^{* * *} p<0.005$.

values of factor loading were above 0.66. Moving onto the other scale, it also yielded 2 factors explaining $76.34 \%$ of the total variance, Cronbach's $\alpha$ values of factors were above 0.9 , and the load of each item is above 0.71 . The results show that the two scales are effective; the items have high factorial weight and good internal consistency. The first dimension, "Technical Driving Ability," mainly examined the ability to operate and control the vehicles. The second one, "Risk Perception Ability," showed the drivers' ability to perceive environmental factors and potential risks. The findings were in line with previous studies relating to driving ability assessment $[24,25]$.

4.2. Factors Influencing Speed Selection Behaviours in Low Illumination. Driver characteristics have also been found to influence speed selection. In terms of demographic variables, gender was significantly correlated with speed selection behaviour, with men driving at a higher speed than their counterparts. This is in line with the results of Sadia et al., who suggested that the average speed of women are relatively lower than the men's and women showing a basic lower speed choice [26]. Research focused on demographic characteristics, finding that men drive generally faster than women, and the young drive faster than older ones $[27,28]$.
However, the impact of age on speed selection behaviour in low illumination without street lights was not significant in the present study. The importance of road safety education for males may promote safer driving.

There are significant differences in terms of driving experience and average annual mileage affecting drivers' speed selection behaviours in a low-illumination environment. Under the same speed limit conditions, the greater the driving experience and the higher the average annual mileage are, the higher the speed selection in a low-illumination environment is. This may be because the more experienced that drivers are, the more confident they are in themselves, believing that they can handle the handling of vehicles and emergencies well even in low-light environments. This is similar with previous findings, such as Spolander proposed that with increased experience, drivers perceive themselves as having higher skills [29] and $\mathrm{Xu}$ et al. suggested that the assessment of perceptualmotor skills improved with increased driving experience [30]. However, research shows that even for drivers with experience, safety education for driving at night still needs to be strengthened [31].

Under the low-illumination condition of street lights at night, the driver's technical driving ability TDA1 has a significant ability to predict the driver's preferred speed on roads with speed limits of $80 \mathrm{~km} / \mathrm{h}$ and $120 \mathrm{~km} / \mathrm{h}$. The 
stronger the technical driving ability is, the faster the speed that the driver tends to choose is, which indicates that a driver with better driving skills believes that he can also complete braking and collision avoidance in a short time and short distance in the case of emergency in a low-illumination environment. However, in low illumination, especially when there are no street lights at night, due to the shortening of the visual range, when a driver discovers obstacles or emergencies, the distance between them is greatly shortened compared with that of high-illumination conditions. It is difficult for drivers driving at a high speed to complete braking within this distance, resulting in collision accidents. Therefore, it is necessary to strengthen the safety education of drivers who have rich driving experience and often drive at night to clarify the dangers of high-speed driving in low illumination.

The risk perception ability in low-illumination conditions with street lights at night RPA1 and the risk perception ability in low-illumination conditions without street lights at night RPA2 are significant predictors of driver speed selection behaviour on roads with speed limits of $80 \mathrm{~km} / \mathrm{h}$ and $120 \mathrm{~km} / \mathrm{h}$, respectively. The stronger the driver's risk perception ability is, the slower speed that the driver tends to choose is, which indicates that a driver with stronger risk perception ability is more cautious when driving in a lowillumination environment and will choose a slower driving speed. In addition, the research results show that in lowillumination conditions with street lights at night, the driver's technical driving ability and risk perception ability have significant predictive ability for speed selection behaviour: the better the technical driving ability is, the faster the speed that the driver tends to choose is; the stronger the risk perception ability is, the lower the speed that the driver tends to choose is. However, in low-illumination conditions without street lights at night, only risk perception ability has a significant predictive ability for speed selection behaviour. This may be because technical driving ability mainly depends on the driver's ability to control the vehicle; however, in the absence of street lights, the driver's visual range is severely limited, and he cannot effectively judge the surrounding environment, which leads to an inability to exert the original driving ability. However, risk perception ability is a psychological state that is more reflected in the driver's awe of traffic safety and subjective cognition. Therefore, for driving safety education at night, we should pay attention not only to the improvement of driving skills but also to the improvement of traffic safety awareness.

The driving speed in a low-illumination environment with street lights has a positive effect on speed selection behaviour in low illumination. The driving speed on a road with a speed limit of $120 \mathrm{~km} / \mathrm{h}$ under a low-illumination environment with street lights has a significant positive effect on speed selection behaviour on roads with speed limits of $60 \mathrm{~km} / \mathrm{h}, 80 \mathrm{~km} / \mathrm{h}$, and $120 \mathrm{~km} / \mathrm{h}$ in low illumination without street lights. Therefore, speed management in a low-illumination environment with street lights should be strengthened, especially for expressways with $120 \mathrm{~km} / \mathrm{h}$ speed limits, where the degree of traffic accident damage is relatively high, to severely punish speeding behaviour, strictly control driving speeds, reduce driving speeds under the condition of low illumination, and reduce the risk of accidents in low illumination and accident severity. Severe punishment for speeding behaviour and strict control of a driver's speed are conducive to reducing the driver's driving speed in low illumination, reducing the accident risk and accident severity in low illumination.

\section{Conclusion}

In this study, a "driver survey questionnaire in low illumination" effectively revealed the influencing factors of driver's speed selection behaviour in low illumination from the driver's perspective. The results show that the education and the total deduction score have a significant negative impact on speed selection behaviour in low illumination without street lights with a speed limit of $80 \mathrm{~km} / \mathrm{h}$, while gender have a significant positive impact. Night-driving days have a significant negative impact on speed selection behaviour in low illumination without street lights with a speed limit of $120 \mathrm{~km} / \mathrm{h}$, while deduction has a significant positive influence. Technical driving ability has a positive effect on peed selection behaviour in low illumination without street lights, while risk perception ability has a negative effect. The driving speed of a driver in a low-illumination environment with street lights has a positive influence on the choice of driving speed in low illumination without street lights, and the driving speed on a road with a speed limit of $120 \mathrm{~km} / \mathrm{h}$ has a significant positive influence on speed selection behaviour on roads with speed limits of $60 \mathrm{~km} / \mathrm{h}, 80 \mathrm{~km} / \mathrm{h}$, and $120 \mathrm{~km} / \mathrm{h}$ under the condition of low illumination without street lights.

This study provides a theoretical foundation for the prevention of speed selection behaviours in a low-illumination environment. Regarding the design of further interventions, the emphasis on road safety education among males and experienced drivers may help promote safer driving in a low-illumination environment.

\section{Limitations}

There are some limitations in this study. This study suffers from the typical limitations of studies based on self-reported data, in which potential vulnerability to sources of bias are present. However, various existing studies have shown that self-reported data are basically consistent with actual data and can be used in experimental research [32]. Another limitation is that the survey was conducted only in Hefei, Anhui, China, and did not cover other cities. Future studies should compare several Chinese cities to validate the conclusions reported here.

\section{Data Availability}

The data used to support the findings of this study have not been made available because we have no right to share it.

\section{Conflicts of Interest}

The authors declare that they have no conflicts of interest. 


\section{References}

[1] A. Gyakov, Night Driving Safety of the Car, China Communications Press, Beijing, China, 1990.

[2] F. Chen and S. Chen, "Injury severities of truck drivers in single- and multi-vehicle accidents on rural highways," Accident Analysis \& Prevention, vol. 43, no. 5, pp. 1677-1688, 2011.

[3] Road Traffic Management Bureau of the Ministry of Public Security, Statistical Annual Report on Road Traffic Accidents of the People's Republic of China, Road Traffic Management Bureau of the Ministry of Public Security, Beijing, China, 2015.

[4] D. A. Owens, J. M. Wood, and J. M. Owens, "Effects of age and illumination on night driving: a road test," Human Factors: The Journal of the Human Factors and Ergonomics Society, vol. 49, no. 6, pp. 1115-1131, 2007.

[5] N. Rackoff and T. Rockwell, Driver Search and Scan Patterns in Night Driving, Transportation Research Board Special Report, Washington, DC, USA, 1975.

[6] Z. X. Feng, Y. W. Lei, H. Z. Yuan, W. H. Zhang, and N. N. Zhang, "Determination method of reasonable driving speed on highway in dynamic low illumination environment," China Journal of Highway and Transport, vol. 28, no. 10, pp. 105-111, 2015.

[7] M. Lyu, The Connection Section between Tunnels and Bridges in Highway Traffic Safety Evaluation Model, Tongji University, Shanghai, China, 2009.

[8] W. Wang, Theory and Method of Driving Behavior in Road Traffic System, Science Press, Berlin, Germany, 2001.

[9] X. Pang, H. Jiang, and A. Gao, "Cause and security counter measures of traffic accident in foggy expressway," Communications Standardization, vol. 10, pp. 200-203, 2006.

[10] W. Zhao, L. Wang, F. Ye et al., "Influence of environmental illuminance of drivers on visual recognition distance," Traffic Information and Safety, vol. 31, no. 6, 2013.

[11] F. Jørgensen and P. A. Pedersen, "Drivers' response to the installation of road lighting. an economic interpretation," Accident Analysis and Prevention, vol. 34, no. 5, pp. 601-608, 2002.

[12] M. Haglund and L. ABerg, "Speed choice in relation to speed limit and influences from other drivers," Transportation Research. Part F: Traffic Psychology and Behaviour, vol. 3, no. 1, pp. 0-51, 2000.

[13] W. Suh, P. Y.-J. Park, C. H. Park, and K. S. Chon, "Relationship between speed, lateral placement, and drivers' eye movement at two-lane rural highways," Journal of Transportation Engineering, vol. 132, no. 8, pp. 649-653, 2006.

[14] R. G. V. Baker, "On the quantum mechanics of optic flow and its application to driving in uncertain environments," Transportation Research Part F: Traffic Psychology and Behaviour, vol. 2, no. 1, pp. 27-53, 1999.

[15] M. Reed and S. Easa, "Effect of luminance on night driving performance of younger-old and older-old adults," International Journal of Research \& Reviews in Applied Sciences, vol. 7, no. 3, pp. 218-227, 2011.

[16] A. Calvi, A. Benedetto, and F. D’Amico, "Investigating driver reaction time and speed during mobile phone conversations with a lead vehicle in front: a driving simulator comprehensive study," Journal of Transportation Safety \& Security, vol. 10, no. 1-2, pp. 5-24, 2018.

[17] F. Chen, S. Chen, and X. Ma, "Analysis of hourly crash likelihood using unbalanced panel data mixed logit model and real-time driving environmental big data," Journal of Safety Research, vol. 65, pp. 153-159, 2018.

[18] Z. Feng, M. Yang, W. Zhang, Y. Du, and H. Bai, "Effect of longitudinal slope of urban underpass tunnels on drivers' heart rate and speed: a study based on a real vehicle experiment," Tunnelling and Underground Space Technology, vol. 81, pp. 525-533, 2018.

[19] F. Chen, M. Song, and X. Ma, "Investigation on the injury severity of drivers in rear-end collisions between cars using a random parameters bivariate ordered probit model," International Journal of Environmental Research and Public Health, vol. 16, no. 14, p. 2632, 2019.

[20] J. Shi, Y. Xiao, L. Tao, and P. Atchley, "Factors causing aberrant driving behaviors: a model of problem drivers in China," Journal of Transportation Safety \& Security, vol. 10, pp. 288-302, 2018.

[21] S. Wu, X. Sun, and Y. He, "A study on the correlation between restricted speed and running speed of graded highways," Traffic Standardization, vol. 23, pp. 50-54, 2010.

[22] D. Zheng, Study on Driver's Risk Perception and Influencing Factors, Shanghai Jiaotong University, Shanghai, China, 2013.

[23] B. L. De Castro, F. J. Gracia, I. Tomás, and J. M. Peiró, "The safety culture enactment questionnaire (SCEQ): theoretical model and empirical validation," Accident Analysis \& Prevention, vol. 103, pp. 44-55, 2017.

[24] K. Wang, W. Zhang, J. Liu et al., "Exploring the factors affecting myopic drivers' driving skills and risk perception in nighttime driving," Cognition Technology and Work, vol. 21, no. 2, pp. 275-285, 2018.

[25] W. Zhang, Z. Hu, Z. Feng, C. Ma, K. Wang, and X. Zhang, "Investigating factors influencing drivers' speed selection behavior under reduced visibility conditions," Traffic Injury Prevention, vol. 19, no. 5, pp. 1-20, 2018.

[26] R. Sadia, S. Bekhor, and A. Polus, "Speed variation for different drivers, situations, and road geometry: simulator and survey analysis," Journal of Transportation Safety \& Security, vol. 10, no. 1-2, pp. 25-44, 2017.

[27] Stichting Wetenschap Onderzoek Verkeersveiligheid (SWOV), SWOV Fact Sheet: Intelligent Speed Assistance (ISA), SWOV: Institute for Road Safety Research, Leidschendam, The Netherlands, 2010.

[28] P. Wasielewski, "Speed as a measure of driver risk: observed speeds versus driver and vehicle characteristics," Accident Analysis \& Prevention, vol. 16, no. 2, pp. 89-103, 1984.

[29] K. Spolander, "Drivers' assessment of their own driving ability," Report No. 252, Swedish National Road and Transport Research Institute (VTI), Linköping, Sweden, 1983.

[30] J. Xu, J. Liu, X. Sun, K. Zhang, W. Qu, and Y. Ge, "The relationship between driving skill and driving behavior: psychometric adaptation of the driver skill inventory in China," Accident Analysis \& Prevention, vol. 120, pp. 92-100, 2018.

[31] G. Cheng, H. Xu, and X. Mo, "The law of drivers' recognition of pedestrians crossing the street at night," Journal of Harbin Institute of Technology, vol. 45, no. 6, pp. 65-70, 2013.

[32] M. Ma, X. Yan, H. Huang, and M. Abdel-Aty, "Safety of public transportation occupational drivers: risk perception, attitudes, and driving behavior," Transportation Research Record: Journal of the Transportation Research Board, vol. 2145, no. 1, pp. 72-79, 2010. 